CLINICAL STUDY

\title{
Outcome in surgically treated Rathke's cleft cysts: long-term monitoring needed
}

\author{
R Trifanescu, V Stavrinides ${ }^{1}$, P Plaha ${ }^{1}$, S Cudlip ${ }^{1}$, J V Byrne ${ }^{2}$, O Ansorge ${ }^{3}$, J A H Wass and N Karavitaki \\ Department of Endocrinology, Oxford Centre for Diabetes, Endocrinology and Metabolism, Churchill Hospital, Old Road, Headington, Oxford OX3 7LJ, UK \\ and Departments of ${ }^{1}$ Neurosurgery, ${ }^{2}$ Neuroradiology and ${ }^{3}$ Neuropathology, John Radcliffe Hospital, Oxford OX3 9DU, UK \\ (Correspondence should be addressed to N Karavitaki; Email: nikikara@doctors.org.uk)
}

\begin{abstract}
Objective: To clarify the outcome of all cases of Rathke's cleft cysts (RCC) treated surgically and followed up in Oxford during a long-term period.

Subjects and methods: The records of all patients with RCC seen in the Department of Endocrinology between January 1978 and June 2009 were reviewed.

Results: A total of 33 patients (20 females, median age 43 years) were identified. At presentation, major visual field defects were detected in $58 \%$ of patients and gonadotrophin, ACTH and TSH deficiency in 60,36 and 36\% of patients respectively. Desmopressin treatment was required in $18 \%$ of patients. Treatment consisted of cyst evacuation combined with or without biopsy/removal of the wall. Post-operatively, visual fields improved in $83 \%$ of patients with impairment, whereas there was no reversal of ACTH or TSH deficiency or of diabetes insipidus. All but one subject had imaging follow-up during a mean period of 48 months (range 2-267). Cyst relapse was detected in $22 \%$ of patients at a mean interval of 29 months (range 3-48 months); in 57\% of them, the recurrence was symptomatic. Relapse-free rates were $88 \%$ at 24 -months and $52 \%$ at 48 -months follow-up. At last assessment, at least quadrantanopia was reported in 19\% of patients, gonadotrophin, ACTH and TSH deficiency in 50, 42 and $47 \%$ of patients respectively. Desmopressin treatment was required in $39 \%$ of patients.

Conclusions: In this study of patients with RCC and long-term follow-up, we showed a considerable relapse rate necessitating long-term monitoring. Surgical intervention is of major importance for the restoration of visual field defects, but it does not improve endocrine morbidity, which in the long-term affects a substantial number of patients.
\end{abstract}

European Journal of Endocrinology $16533-37$

\section{Introduction}

Rathke's cleft cysts (RCCs) are benign lesions of the pituitary region typically lying within the pars intermedia. They are the most common incidentally discovered sellar lesions, followed by pituitary adenomas (1), and are found in $13-33 \%$ of routine autopsies (2). They present as intra-sellar cysts with $60 \%$ of them showing suprasellar extension (3). Their size ranges between a few $\mathrm{mm}$ to $10-20 \mathrm{~mm}$; cases with a cyst size up to 45-50 $\mathrm{mm}$ have also been described (3).

Symptomatic RCCs are rare (4), and their clinical manifestations are associated with pressure effects on adjacent structures. Cyst evacuation combined with or without biopsy/removal of the cyst wall is the optimal management strategy for symptomatic cases (5-8) resulting in improvement of headaches and the visual disturbances $(5,7)$.

It has been proposed that craniopharyngiomas and RCCs may represent a continuum of ectodermally derived epithelial lesions (9). Nevertheless, the prognosis of RCCs following surgical intervention is more favourable than that of craniopharyngiomas (10), with reported relapse rates ranging widely between 0 and $42 \%$ during variable follow-up periods $(4,5,11-14)$. It should be noted, however, that the published studies mainly involve small number of patients or short observation intervals, potentially compromising the practical clinical value of their results. Given the advances in neuroimaging techniques, it is anticipated that the detection rate of RCCs will increase necessitating evidence-based guidelines on their management and follow-up.

The aim of our study was to clarify the outcome (in terms of pituitary function and recurrence) of 33 cases of RCCs treated surgically and followed up in our department for a mean period of 48 months (range 2-267) - one of the longest reported observation periods. 
Table 1 Clinical features at diagnosis (data are presented as the number of patients and the relevant percentages).

\begin{tabular}{|c|c|c|}
\hline Symptoms & No. of patients & Percentage \\
\hline Headache & $22 / 33$ & 67 \\
\hline Major visual field defects ${ }^{a}$ & $19 / 33$ & 58 \\
\hline Impaired sexual function & $19 / 33$ & 58 \\
\hline Poor energy & $19 / 33$ & 58 \\
\hline Polyuria & $8 / 33$ & 24 \\
\hline Low mood & $7 / 33$ & 21 \\
\hline Galactorrhoea & $4 / 20^{b}$ & 20 \\
\hline Nausea & $6 / 33$ & 18 \\
\hline Vomiting & $4 / 33$ & 12 \\
\hline Dizziness & $3 / 33$ & 9 \\
\hline Poor concentration/memory & $3 / 33$ & 9 \\
\hline Growth failure & $1 / 1^{c}$ & 100 \\
\hline
\end{tabular}

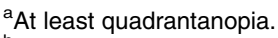

${ }^{\mathrm{b}}$ Females.

${ }^{\mathrm{c} C h i l d \text {. }}$

\section{Subjects and methods}

\section{Subjects}

The medical records of all patients who presented with RCC to the Department of Endocrinology in Oxford between January 1978 and June 2009 were studied. The subjects were accessed from the departmental database, on which the patients are classified according to diagnosis. The diagnosis was based on histological verification except in four cases, in which it was established based on combination of pathological, imaging and intra-operative findings.

Imaging data at presentation were available for all patients (CT: 7 and MRI: 26).

Gonadotrophin deficiency was diagnosed on the basis of low or 'inappropriately normal' FSH and LH levels combined with serum testosterone below the reference values in adult men and with low serum oestradiol and oligo/amenorrhoea in adult women. ACTH deficiency was defined by peak cortisol $<580 \mathrm{nmol} / \mathrm{l}$ after provocative testing (insulin tolerance test, glucagon or short Synacthen test) or as a random morning serum cortisol value $<100 \mathrm{nmol} / \mathrm{l}$ (in the absence of steroid therapy). TSH deficiency was defined by low or 'inappropriately normal' TSH with thyroid hormone levels below the normal reference values. Diabetes insipidus was diagnosed on the basis of urine output $>3 \mathrm{l} / 24 \mathrm{~h}$ and urine osmolality $<300 \mathrm{mOsm} / \mathrm{kg}$.

Follow-up imaging was performed at 2-3 months post-operatively and every 1-3 years thereafter. Recurrence was diagnosed on the basis of radiological appearances with or without associated signs and symptoms.

\section{Statistical analyses}

All evaluations were based on the number of patients with available data. The recurrence-free curves were generated by the Kaplan-Meier method. Differences in the recurrence rates between sub-groups were analysed by the log-rank test. Statistical analyses were performed by the SPSS 19.0 for Windows (SPSS, Inc., Chicago, IL, USA).

\section{Results}

A total of 33 patients ( 13 males/20 females, median age at diagnosis 43 years (range 9-87)) were identified. Of the total subjects, $88 \%$ presented in the second half of the recruitment period. The median duration of signs and symptoms at presentation was 12 months (range 0.25-120 months). The presenting clinical features (as documented in the medical notes but not according to a standardised questionnaire) of the patients are shown in Table 1. Acute symptoms mimicking pituitary apoplexy were reported in three subjects. The pituitary function at presentation is shown in Table 2. All but three cysts had an extrasellar component (30/33, 90\%).

The patients were treated by cyst evacuation combined with or without biopsy/removal of the cyst wall (3/33 via craniotomy and 30/33 transsphenoidally). In five cases, the RCC was co-existent with a pituitary adenoma (one 'chromophobe', one gonadotroph, two corticotrophs and one prolactinoma); among them, the RCC was an incidental finding in three subjects (one 'chromophobe' and two corticotrophs) and one patient received adjuvant radiotherapy (10 months after surgery, 50 Gy in 27 fractions).

Table 2 Pituitary function at presentation, post-operatively and at the last assessment (data are presented as the number of patients and the relevant percentages - two patients with Cushing's disease have been excluded from the anterior pituitary function evaluations).

\begin{tabular}{|c|c|c|c|}
\hline & $\begin{array}{c}\text { At } \\
\text { presentation }\end{array}$ & Post-operatively & $\begin{array}{c}\text { Last } \\
\text { assessment }\end{array}$ \\
\hline FSH/LH deficiency ${ }^{\mathrm{a}}$ & $60 \%(18 / 30)$ & $52 \%(14 / 27)$ & $50 \%(15 / 30)$ \\
\hline ACTH deficiency & $36 \%(10 / 28)$ & $43 \%(13 / 30)$ & $42 \%(13 / 31)$ \\
\hline TSH deficiency & $36 \%(11 / 29)$ & $43 \%(12 / 28)$ & $47 \%(14 / 30)$ \\
\hline On desmopressin & $18 \%(5 / 27)$ & $39 \%(13 / 33)$ & $39 \%(13 / 33)$ \\
\hline Hyperprolactinaemia & $31 \%(9 / 27)$ & & \\
\hline
\end{tabular}

${ }^{\mathrm{a} O n e}$ child was excluded. 
Following surgery, $38 \%(11 / 29)$ of the subjects had major visual field defects (prior to surgery 58\% $(19 / 33)$ ). Visual fields improved in $83 \%$ of patients $(15 / 18)$ and remained stable in 3/18 (17\%) of patients with impairment prior to neurosurgery. The pituitary function post-operatively is shown in Table 2. Gonadotrophin deficiency resolved in two cases following restoration of normoprolactinaemia, although there was no reversal of ACTH or TSH deficiency or of diabetes insipidus in any patient.

All but one patient had scans after surgery during a mean observation period of 48 months (range 2-267). Cyst relapse was detected in $22 \%(7 / 32)$ of the cases at a mean interval following surgery of 29 months (range 3-48 months); in 4/7 (57\%) subjects, the recurrence was symptomatic (headaches and/or visual fields defects). Kaplan-Meier analysis showed relapse-free survival rates of 93,88 and $52 \%$ at 12,24 and 48 months respectively (Fig. 1). There was no difference in the relapse-free rates between patients investigated preoperatively with CT or with MRI.

All but one recurrence were managed by repeat surgery (cyst evacuation combined with or without removal of cyst wall $-1 / 6$ via craniotomy and 5/6 transsphenoidally) and one subject had multiple relapses requiring four transsphenoidal operations.

At the last assessment, at least quadrantanopia was reported in $6 / 31(19 \%)$ of the whole group of patients and in $1 / 6(17 \%)$ of those with relapse. The pituitary function at last evaluation for the whole group of patients and for those with relapse is shown in Tables 2 and 3 respectively.

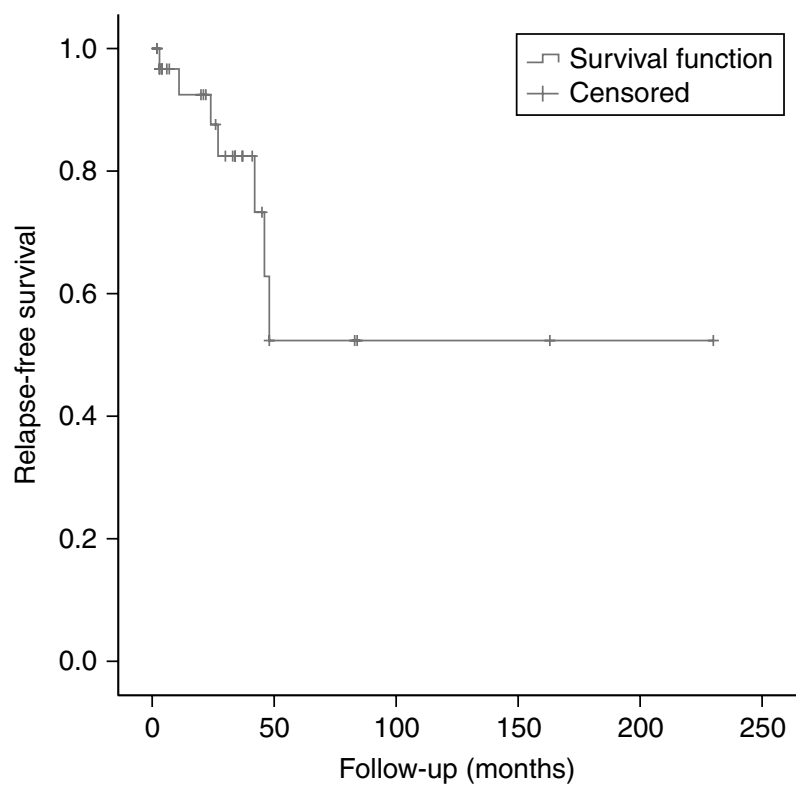

Figure 1 Recurrence-free probability following surgical management of RCC $(n=32)$.
Table 3 Pituitary function at presentation and at the last assessment in patients with relapse (data are presented as the number of patients and the relevant percentages).

\begin{tabular}{lcc}
\hline & At presentation & Last assessment \\
\hline FSH/LH deficiency $^{\mathrm{a}}$ & $67 \%(4 / 6)$ & $83 \%(5 / 6)$ \\
ACTH deficiency & $50 \%(3 / 6)$ & $57 \%(4 / 7)$ \\
TSH deficiency & $50 \%(3 / 6)$ & $57 \%(4 / 7)$ \\
On desmopressin & $50 \%(3 / 6)$ & $71 \%(5 / 7)$ \\
\hline
\end{tabular}

${ }^{a}$ One child was excluded.

\section{Discussion}

In this large study of patients with RCC treated surgically and monitored for one of the longest reported follow-up periods, we have shown a relapse rate of $48 \%$ at 48 months and considerable endocrine morbidity.

RCCs arise from remnants of the Rathke's pouch, a structure apparent during the third week of gestation and formed by the infolding of simple ciliated columnar epithelium lining the roof of the stomodeum. Rathke's pouch extends cranially to form the craniopharyngeal duct; its anterior and posterior walls give rise to the anterior and intermediate lobes of the pituitary gland respectively. The obliteration of the craniopharyngeal duct is associated with the involution of Rathke's pouch. Failure of obliteration of the lumen results in the development of a cyst at the site of the vestigial intermediate lobe in humans (15). Symptomatic RCCs are rare (4) and the manifestations are the result of compression to adjacent structures. In our study, the median duration of symptoms was 12 months, ranging between 0.25 and 120 months; this is in accord with previously published data, in which the mean duration of symptoms/signs was 9-24 months $(4,12,14,16)$. Notably, an acute presentation mimicking pituitary apoplexy was found in three of our patients; similar cases have been infrequently described $(14,17,18)$. Headache was the most common clinical feature at presentation $(67 \%)$, in accord with previously reported studies $(55-81 \%)(4,11,13,14,16,19-23)$. It has been proposed that the presence of headaches does not correlate with the cyst size and it is more common in patients with high and iso-intense cyst content on T1-weighted MR images, with mucous cyst content and with intense chronic inflammation of the cyst wall (21). Major visual field defects were identified in $58 \%$ of the subjects. In previous studies, the frequency ranges between 38 and $49 \%(4,5,12,14,16,20,22)$ with the size of the cyst correlating with the presence of visual deterioration (20). At presentation, the reported rates of pituitary hormone deficits show wide variation (17-81\%) also depending on the method of assessment $(5,11,12,14,16,19,20,22,23)$. We found gonadotrophin deficiency in $60 \%$, ACTH deficiency in $36 \%$, TSH deficiency in $36 \%$ and DI $18 \%$ of our cases, suggesting substantial endocrine morbidity. It has been proposed that anterior hypopituitarism is not related to 
the cyst size and is observed only in cysts with high and iso-intensity on T1-weighted MR images (20). Notably, syndrome of inappropriate secretion of ADH has also been rarely reported $(4,20,22)$.

In five of our cases, the RCC co-existed with a pituitary adenoma. Similar findings have previously been described (24). Despite the common ancestry of pituitary adenomas on the one hand and RCCs on the other, the co-existence of these lesions may be entirely coincidental.

Surgical intervention improves visual field defects in a considerable number of patients; in our study, $83 \%$ of the subjects with major visual field deficits showed improvement, a percentage comparable with other reports $(59-100 \%)(5,7,12,14,16,20,21,23)$. In contrast to pituitary adenomas, and similarly to craniopharyngiomas (10), recovery of anterior pituitary hormone deficits following surgery is not common $(5,12,14,16,20)$. In our study, apart from restoration of hypogonadism attributed to hyperprolactinaemia, we found no reversal of ACTH or TSH deficiency or of diabetes insipidus. Furthermore, at the last assessment, FSH/LH, ACTH and TSH deficiency and diabetes insipidus were found in 50,42 and $47 \%$ of the patients respectively. The poor endocrine prognosis is probably related to pituitary damage attributed to chronic pressure by the cyst, to chronic inflammation following cyst rupture or a result of surgery $(14,20,23,25,26)$. Interestingly, it has been suggested that $4-30 \%$ of the patients will develop new pituitary hormone deficits post-operatively $(8,11,12,23,27)$ and that the degree of endocrine morbidity is higher after aggressive surgery (5). At the last assessment, 39\% of our patients required desmopressin; in previous studies, this ranged between 2 and $42 \%(5,7,8,11-13,20,22,23,28)$. Interestingly, in a study of 857 patients who underwent transsphenoidal microsurgery, those with an intraoperative cerebrospinal fluid (CSF) leak, with a craniopharyngioma or with an RCC were at higher risk for persistent diabetes insipidus (28). Diabetes insipidus is also more frequent after radical cyst resection, compared with less aggressive surgery (42 vs $9 \%$ ) (5).

Relapse results from re-accumulation of the cyst fluid and it has usually been detected within 5-6 years following surgery; notably, recurrences up to 24 years post-operatively have been reported $(5,11-14,19,22)$. In our study, during a mean follow-up period of 4 years (and within the constraints of the lower limit of our observation interval (2 months)), relapse was found in $22 \%$ of the patients at a mean interval of 29 months after operation and in $57 \%$ of the cases, this was symptomatic. Previously reported data, most of which are based on relatively short observation periods, show recurrence rates ranging between 0 and $33 \%(4,5,11$, 12, 20, 23). In our study, at the 2-year follow-up, the relapse-free rate was $88 \%$, and at 4 years, this considerably decreased to $52 \%$, suggesting that longterm monitoring is necessary. Factors proposed to be associated with an increased risk of recurrence include the use of fat and/or fascial graft for sellar fossa closure (5), presence of squamous metaplasia of the cyst wall $(5,7,14)$, presence of inflammation (7), cyst size (12) and enhancement of the lesion on MRI images (14). Although not widely accepted (5), aggressive resection of cyst wall may prevent relapse (14), but may also be associated with higher rate of post-operative complications $(5,7)$. Of the total patients, one had multiple relapses requiring four surgical interventions; although such aggressive behaviour has previously been reported $(16,22)$, it is very rare.

In this study of patients with RCC followed up for a mean period of 4 years, we have shown that despite the benign pathological appearance of these lesions, there is a considerable relapse rate importantly necessitating long-term monitoring. Surgical intervention is of major importance for the restoration of visual field defects but does not improve endocrine morbidity. Given the rarity of this condition in clinical practice, national databases are needed aiming to provide evidence-based guidelines on management and long-term outcome.

\section{Declaration of interest}

The authors declare that there is no conflict of interest that could be perceived as prejudicing the impartiality of the research reported.

\section{Funding}

This research did not receive any specific grant from any funding agency in the public, commercial or not-for-profit sector.

\section{References}

1 Teramoto A, Hirakawa K, Sanno N \& Osamura Y. Incidental pituitary lesions in 1,000 unselected autopsy specimens. Radiology 1994193 161-164.

2 Osborn AG \& Preece MT. Intracranial cysts: radiologic-pathologic correlation and imaging approach. Radiology 2006239 650-664. (doi:10.1148/radiol.2393050823)

3 Karavitaki N \& Wass JA. Non-adenomatous pituitary tumours. Best Practice and Research. Clinical Endocrinology and Metabolism 200923 651-665. (doi:10.1016/j.beem.2009.05.007)

4 Mukherjee JJ, Islam N, Kaltsas G, Lowe DG, Charlesworth M, Afshar F, Trainer PJ, Monson JP, Besser GM \& Grossman AB. Clinical, radiological and pathological features of patients with Rathke's cleft cysts: tumors that may recur. Journal of Clinical Endocrinology and Metabolism 199782 2357-2362. (doi:10. $1210 /$ jc.82.7.2357)

5 Aho CJ, Liu C, Zelman V, Couldwell WT \& Weiss MH. Surgical outcomes in 118 patients with Rathke cleft cysts. Journal of Neurosurgery 2005102 189-193. (doi:10.3171/jns.2005.102.2. 0189)

6 Baskin DS \& Wilson CB. Transsphenoidal treatment of nonneoplastic intrasellar cysts. A report of 38 cases. Journal of Neurosurgery 198460 8-13. (doi:10.3171/jns.1984.60.1.0008)

7 Benveniste RJ, King WA, Walsh J, Lee JS, Naidich TP \& Post KD. Surgery for Rathke cleft cysts: technical considerations and outcomes. Journal of Neurosurgery 2004101 577-584. (doi:10. 3171/jns.2004.101.4.0577) 
8 el-Mahdy W \& Powell M. Transsphenoidal management of 28 symptomatic Rathke's cleft cysts, with special reference to visual and hormonal recovery. Neurosurgery 199842 7-16. (doi:10. 1097/00006123-199801000-00003)

9 Harrison MJ, Morgello S \& Post KD. Epithelial cystic lesions of the sellar and parasellar region: a continuum of ectodermal derivatives? Journal of Neurosurgery 199480 1018-1025. (doi:10. 3171/jns.1994.80.6.1018)

10 Karavitaki N, Brufani C, Warner JT, Adams CB, Richards P, Ansorge O, Shine B, Turner HE \& Wass JA. Craniopharyngiomas in children and adults: systematic analysis of 121 cases with longterm follow-up. Clinical Endocrinology 200562 397-409. (doi:10. $1111 /$ j.1365-2265.2005.02231.x)

11 Zada G, Ditty B, McNatt SA, McComb JG \& Krieger MD. Surgical treatment of Rathke cleft cysts in children. Neurosurgery 200964 1132-1137. (doi:10.1227/01.NEU.0000341873.20737.56)

12 Shin JL, Asa SL, Woodhouse LJ, Smyth HS \& Ezzat S. Cystic lesions of the pituitary: clinicopathological features distinguishing craniopharyngioma, Rathke's cleft cyst, and arachnoid cyst. Journal of Clinical Endocrinology and Metabolism $1999 \mathbf{8 4}$ 3972-3982. (doi:10.1210/jc.84.11.3972)

13 Koutourousiou M, Grotenhuis A, Kontogeorgos G \& Seretis A. Treatment of Rathke's cleft cysts: experience at a single centre. Journal of Clinical Neuroscience 200916 900-903. (doi:10.1016/j. jocn.2008.10.007)

14 Kim JE, Kim JH, Kim OL, Paek SH, Kim DG, Chi JG \& Jung HW. Surgical treatment of symptomatic Rathke cleft cysts: clinical features and results with special attention to recurrence. Journal of Neurosurgery 2004100 33-40. (doi:10.3171/jns.2004.100.1. 0033)

15 Karavitaki N. Benign cysts: Rathke's cysts, mucoceles, arachnoid cysts, and dermoid and epidermoid cysts. In Clinical Endocrine Oncology, 2nd edn, ch 37, pp 288-292. Eds Ian D Hay \& John AH Wass. Oxford, UK: Blackwell Publishing Ltd. 2009. (doi:10.1002/ 9781444300222.ch37)

16 Billeci D, Marton E, Tripodi M, Orvieto E \& Longatti P. Symptomatic Rathke's cleft cysts: a radiological, surgical and pathological review. Pituitary 20047 131-137. (doi:10.1007/ s11102-005-1755-3)

17 Binning MJ, Liu JK, Gannon J, Osborn AG \& Couldwell WT. Hemorrhagic and nonhemorrhagic Rathke cleft cysts mimicking pituitary apoplexy. Journal of Neurosurgery 2008108 3-8. (doi:10. 3171/JNS/2008/108/01/0003)

18 Nishioka H, Ito H, Miki T, Hashimoto T, Nojima H \& Matsumura H. Rathke's cleft cyst with pituitary apoplexy: case report. Neuroradiology 199941 832-834. (doi:10.1007/s002340050851)
19 Kasperbauer JL, Orvidas LJ, Atkinson JL \& Abboud CF. Rathke cleft cyst: diagnostic and therapeutic considerations. Laryngoscope 2002112 1836-1839. (doi:10.1097/00005537-200210000$00024)$

20 Nishioka H, Haraoka J, Izawa H \& Ikeda Y. Magnetic resonance imaging, clinical manifestations, and management of Rathke's cleft cyst. Clinical Endocrinology 200664 184-188. (doi:10.1111/ j.1365-2265.2006.02446.x)

21 Nishioka H, Haraoka J, Izawa H \& Ikeda Y. Headaches associated with Rathke's cleft cyst. Headache 200646 1580-1586. (doi:10. 1111/j.1526-4610.2006.00539.x)

22 Raper DM \& Besser M. Clinical features, management and recurrence of symptomatic Rathke's cleft cyst. Journal of Clinical Neuroscience 200916 385-389. (doi:10.1016/j.jocn.2008.04. 023)

23 Sade B, Albrecht S, Assimakopoulos P, Vezina JL \& Mohr G. Management of Rathke's cleft cysts. Surgical Neurology 200563 459-466. (doi:10.1016/j.surneu.2004.06.014)

24 Karavitaki N, Scheithauer BW, Watt J, Ansorge O, Moschopoulos M, Llaguno AV \& Wass JA. Collision lesions of the sella: co-existence of craniopharyngioma with gonadotroph adenoma and of Rathke's cleft cyst with corticotroph adenoma. Pituitary 200811 317-323. (doi:10.1007/s11102007-0070-6)

25 Hama S, Arita K, Nishisaka T, Fukuhara T, Tominaga A, Sugiyama K, Yoshioka H, Eguchi K, Sumida M, Heike Y \& Kurisu K. Changes in the epithelium of Rathke cleft cyst associated with inflammation. Journal of Neurosurgery 200296 209-216. (doi:10.3171/jns.2002.96.2.0209)

26 Yoon JW, Jo SK, Cha DR, Cho WY \& Kim HK. A case of Rathke's cleft cyst inflammation presenting with diabetes insipidus. Korean Journal of Internal Medicine 200116 132-135.

27 Voelker JL, Campbell RL \& Muller J. Clinical, radiographic, and pathological features of symptomatic Rathke's cleft cysts. Journal of Neurosurgery 199174 535-544. (doi:10.3171/jns.1991.74.4. 0535)

28 Nemergut EC, Zuo Z, Jane JA Jr \& Laws ER Jr. Predictors of diabetes insipidus after transsphenoidal surgery: a review of 881 patients. Journal of Neurosurgery 2005103 448-454. (doi:10.3171/jns. 2005.103.3.0448)

Received 30 March 2011

Accepted 18 April 2011 